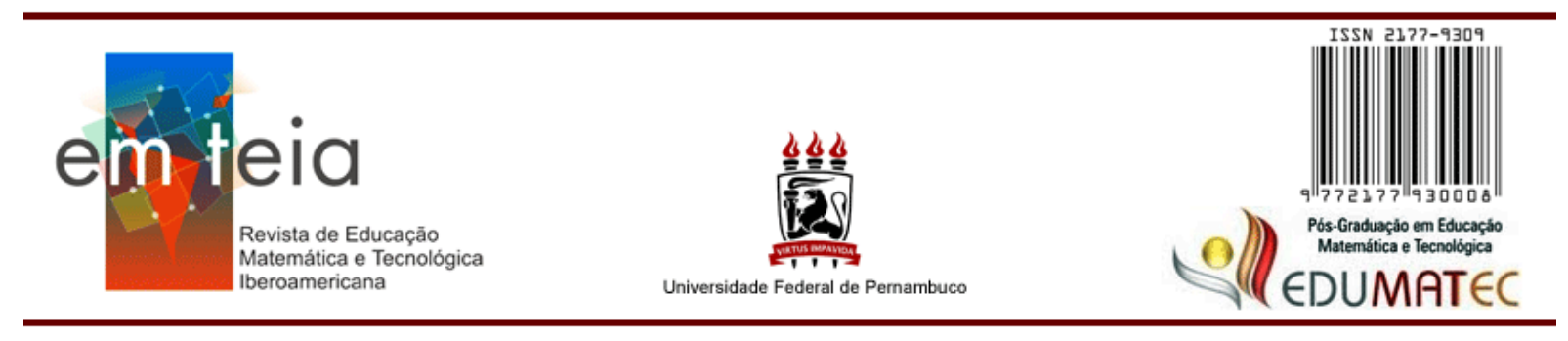

\title{
EDUCAÇÃO MATEMÁTICA E SUAS ARTICULAÇÕES COM A TECNOCIÊNCIA: UM ESTUDO DO CURRÍCULO ESCOLAR DO ENSINO TÉCNICO AGRÍCOLA
}

\author{
Neila de Toledo e Toledo \\ Doutora \\ IFC Rio do Sul-SC-Brasil \\ neila.toledo@ifc.edu.br
}

\begin{abstract}
Resumo
O artigo é fruto de uma investigação desenvolvida com o propósito de examinar os efeitos do discurso da tecnociência presentes na educação matemática praticada na disciplina de Matemática e nas disciplinas técnicas do curso Técnico em Agropecuária do IFRS-Sertão. Os aportes teóricos que dão sustentação à analítica empreendida no trabalho advêm, principalmente, das noções de Michel Foucault e seus comentadores. O material de pesquisa foi produzido a partir de entrevistas com egressos do curso - da década de 1980 e da atualidade - documentos institucionais e materiais escolares (cadernos e avaliações da disciplina de Matemática dos dois momentos estudados). A análise desse material mostrou que: nas últimas três décadas, a lista de conteúdos da disciplina de Matemática não se alterou, a educação matemática da disciplina Matemática manteve sua abordagem abstrata e formal, e a educação matemática presente nas disciplinas técnicas alinhou-se com o discurso da tecnociência, incluindo recursos tecnológicos.
\end{abstract}

Palavras-Chave: Educação Matemática. Currículo. Curso Técnico Agrícola. Tecnociência. Matemática.

\begin{abstract}
The article is the result of an investigation developed with the purpose of examining the effects of the technoscience discourse present in mathematical education practiced in the discipline of mathematics and in the technical disciplines of the Technical course in Agriculture at IFRS-Sertão. The theoretical contributions that support the analytics undertaken in the work come mainly from the notions of Michel Foucault and his commentators. The research material was produced from interviews with graduates of the course - from the 1980s and today - institutional documents and school materials (notebooks and evaluations of the mathematics discipline of the two studied moments. The analysis of this material showed that: in the last three decades, the list of contents of the Mathematics discipline has not changed, the mathematical education of the Mathematical discipline has maintained its abstract and formal approach, and the mathematical education present in the technical disciplines has aligned with the discourse of technoscience, including technological resources.
\end{abstract}

Keywords: Mathematics Education. Curriculum. Agricultural Technical Course. Technoscience. Mathematics. 


\section{Introdução}

Este artigo apresenta os resultados de uma pesquisa desenvolvida com o propósito de analisar os efeitos do discurso da tecnociência presentes na educação matemática praticada na disciplina de matemática e nas disciplinas técnicas do curso Técnico em Agropecuária do IFRS-Sertão ${ }^{1}$ na década de $1980^{2}$ e na atualidade (no período de 2008 até 2015). Para isso, o

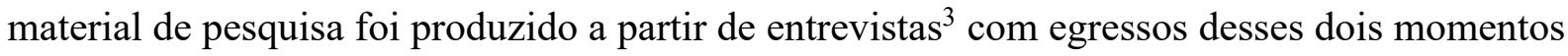
e de documentos institucionais. As bases teóricas que, neste estudo, sustentam o exercício analítico empreendido sobre o material de pesquisa estão construídas a partir, principalmente, de noções advindas de Michel Foucault e seus comentadores.

Nas últimas décadas, o capitalismo e a ciência, por meio da nanotecnologia, biotecnologia, tecnologia digital etc., interferem e acarretam transformações nos modos de conceber a vida e de fazer ciência (BOCASANTA; KNIJNIK, 2016). Esse novo entendimento de ciência que emergiu junto com a modernidade, nomeada por Latour (2011) como tecnociência, provocou mudanças na prática científica, de modo que o conhecimento científico deixou de ser entendido como um fim e um bem em si mesmo, para se transformar em um meio para outras finalidades (econômicas, políticas e sociais).

A tecnociência contemporânea representa o entrelaçamento da produção de conhecimento científico, das técnicas e do capitalismo no interior da racionalidade neoliberal vigente (TOLEDO, 2017). Na atualidade, estudos (BOCASANTA; KNIJNIK, 2016; SILVA, 2011) mostram o lugar privilegiado que a educação escolarizada e não escolarizada ocupa na busca de tecnocientifizar (todos) os indivíduos e a sociedade, ou seja, a tecnociência em nossos tempos é posicionada no centro do processo educativo como um meio de garantia do progresso socioeconômico do indivíduo e da nação. Cabe, então, indagar: como a formação

${ }^{1}$ O Instituto Federal de Educação, Ciência e Tecnologia do Rio Grande do Sul Campus Sertão (IFRS-Sertão) se originou da Escola Agrotécnica Federal de Sertão (EAFS), em decorrência do plano de reconfiguração da Rede Federal de Educação Profissional e Tecnológica (RFEPT), desencadeado juntamente com a política de sua expansão, na criação dos IFs no Brasil. A instituição localiza-se no munícipio de Sertão (RS) (TOLEDO, 2017).

${ }^{2}$ A escolha por esse recorte temporal e não outro deu-se em função de ter sido os anos 80 o marco principal da modernização do campo brasileiro. Já a opção pelo momento atual, a partir dos anos de 2000, porque foi nesse momento que ocorreu a significativa expansão dessa modernização (FILHO, 2014; SILVEIRA, 2014).

${ }^{3}$ Este estudo tem o parecer favorável do Comitê de Ética em Pesquisa da Unisinos e o Termo de Consentimento Livre e Esclarecido, deliberado pelo Comitê. No início de cada entrevista, apresentei os objetivos e procedimentos da pesquisa, para depois solicitar a assinatura do Termo de Consentimento Livre e Esclarecido, de acordo com as normas de ética nas pesquisas em Ciências Humanas e Sociais. Para preservar o anonimato dos participantes da pesquisa, escolhi identificá-los ao longo da pesquisa como Carlos, Luis, Pedro, João, Paula e Felipe quando se trata do período da década de 1980 e como Jean, Gabriel e Maria quando analiso o que chamo de momento atual (de 2008 até 2015). 
do técnico agrícola do IFRS-Sertão é atingida por essas configurações? Em particular, na área da educação matemática, como isso se realiza?

Com o intuito de responder as questões elencadas acima, escolhi estruturar o artigo em cinco partes. Na primeira, discorro sobre o processo de produção do material de pesquisa e o referencial teórico-metodológico. $\mathrm{Na}$ segunda, trago brevemente o conceito de tecnociência usado no texto. Na terceira, descrevo alguns dos efeitos produzidos pelo discurso da tecnociência no currículo do Curso Técnico estudado aqui. Na quarta, o propósito é mostrar os efeitos do discurso da tecnociência presentes na educação matemática praticada na disciplina de matemática e nas disciplinas técnicas. Na quinta, e última parte, teço algumas considerações acerca do que proponho neste estudo. Diante do exposto, saliento que para atingir os objetivos propostos em cada sessão e assim responder as questões destacadas acima, faço uso do material de pesquisa produzido neste estudo no decorrer de cada seção trabalhada.

\section{Caminho Teórico-Metodológico}

Para fins de análise, no presente estudo, foram considerados como material de pesquisa entrevistas com 3 recém-formados e 2 ex-alunos que frequentaram o curso nos anos 80, documentos institucionais e materiais escolares (cadernos e avaliações da disciplina de matemática) desses alunos. A estratégia analítica posta em ação para operar com esse material orientou-se pela análise do discurso em uma perspectiva foucaultiana associada à abordagem metodológica de storytelling.

Seguindo as formulações de Foucault, considero a noção de discurso "como práticas que formam sistematicamente os objetos de que falam" (FOUCAULT, 2013, p. 60), e não como um "[...] puro e simples entrecruzamento de coisas e palavras: trama obscura das coisas, cadeia manifesta, visível e colorida das palavras" (FOUCAULT, 2013, p. 59). Para o filósofo, discurso é "[...] um conjunto de enunciados que se apoiem na mesma formação discursiva" ou um "número limitado de enunciados para os quais podemos definir um conjunto de condições de existência" (FOUCAULT, 2013, p. 143).

O autor compreende por formação discursiva ou sistema de formação: “[...] um feixe complexo de relações que funcionam como regra: ele prescreve o que deve ser correlacionado em uma prática discursiva, para que esta se refira a tal ou qual objeto, para que empregue tal ou qual enunciação, para que utilize tal conceito, para que organize tal ou qual estratégia" (FOUCAULT, 2013, p. 82). Ou seja, quando falamos em discurso econômico, político, feminista, psiquiátrico, médico ou pedagógico, estamos demarcando que cada um deles faz 
parte de um conjunto de enunciados, vinculado a um determinado sistema de formação ou formação discursiva: da economia, da ciência política, da medicina, da pedagogia, da psiquiatria (FISCHER, 2012).

No decorrer das entrevistas, escolhi, inspirada em Souza (2015, p. 48), formular uma questão (chamada pelo autor de "motivadora") para dar início às entrevistas, seguida de outras perguntas cujas respostas poderiam contribuir para a investigação. A questão "motivadora" foi: "relate sobre a sua formação no curso Técnico em Agropecuária - IFRS-Sertão: que lembranças o curso traz à tona?”. A partir dela, os participantes narraram sua trajetória profissional como técnicos agrícolas e detalharam sua formação no IFRS, comentando sobre as aulas das disciplinas da formação técnica e da formação básica e relatando o que a instituição representou ou representa para suas vidas.

A concepção de entrevista que segui na produção e análise do material de pesquisa insere-se na perspectiva da storytelling, conforme é compreendida por Jørgensen e Strand (2014). A storytelling reúne múltiplas vozes (vozes de instituições, governos, comunidades, profissionais, vozes de homens, mulheres e crianças, de culturas etc.), examinando-as de modo não-linear. Nessa abordagem, as histórias são consideradas como produzidas no interior de um dispositivo e, assim, estão imbricadas em relações de poder (JØRGENSEN; STRAND, 2014). Para os autores, são histórias, pequenas ou grandes, que estão emaranhadas com o mundo, em várias direções, e, por isso, podem mostrar várias forças atuando na composição das histórias contadas (JØRGENSEN; STRAND, 2014).

Cada uma das entrevistas foi gravada após autorização para tal e transcritas na íntegra. Cada uma das entrevistas teve duração aproximada de 200 minutos. A respeito da escolha dos recém-formados técnicos agrícolas do Campus Sertão, destaco que os três foram indicados por um professor da instituição, da área de formação técnica, que os conhecia por terem sido alunos que se destacavam na participação, muitas vezes voluntária, em projetos de pesquisa e extensão e em monitorias das disciplinas. As entrevistas com os recém-formados, por escolha deles, foram feitas na universidade em que estudavam na época e foram realizadas individualmente, em um laboratório da instituição, onde um deles trabalhava. Todos eles haviam sido meus alunos. Percebo que isso contribuiu para sua aceitação em participar da pesquisa.

Os egressos da década de 1980 foram selecionados a partir da indicação de uma professora do Campus que é natural de Selbach. Ela repassou o contato de um dos egressos, que era secretário da agricultura na época. Este, por sua vez, pessoa conhecida no município, 
tendo sido vereador e assumido outros cargos na prefeitura municipal, colocou-me em contato com outros egressos. Com o número de telefone de 15 pessoas, iniciei os contatos para saber quem estava morando no município de Selbach e teria interesse em participar da pesquisa; das pessoas contatadas, somente oito ainda estavam residindo no município e, destas, seis aceitaram participar desta pesquisa. Decidi entrevistar só as pessoas que residiam em Selbach, pois ficaria mais acessível o deslocamento para as entrevistas.

As seis pessoas que aceitaram participar da pesquisa residiam ou na cidade, ou no interior do município de Selbach. Uma das dificuldades encontradas para agendar as entrevistas foi que, no final de outubro, muitos dos participantes da pesquisa estavam envolvidos, direta ou indiretamente, no preparo do solo para o plantio da soja; por isso, as entrevistas foram marcadas em dias de chuva ou após a época de plantio. A primeira entrevista foi realizada no dia 1 de dezembro de 2013, com o seu Luis que foi mediador no processo de localização dos participantes da pesquisa, e aconteceu em seu local de trabalho. É pertinente ressaltar que foi por méritos dessa pessoa que consegui, mesmo sendo uma desconhecida no município de Selbach, ter acesso aos lares dos participantes da pesquisa. Outro fator que contribuiu para a receptividade e hospitalidade que tive foi ser professora no IFRS-Sertão; acredito que isso abriu "as portas" das casas e me ajudou a conquistar a confiança desses egressos, que não fingem o "orgulho e gratidão" por ter feito parte, como eles designam, da "família EAFS".

Logo após as primeiras análises das transcrições, organizei os dados em uma tabela que possibilitou conhecer, mais detalhadamente, as informações contidas em tais entrevistas, o que foi me oportunizando fazer cruzamentos e perceber recorrências discursivas entre esses dados. Em seguida, resolvi voltar a entrar em contato com dois dos entrevistados com a finalidade de esclarecer melhor alguns aspectos e fazer "novas" perguntas.

A recém-formada, Maria, entregou a mim, no primeiro contato que fiz com ela, em agosto de 2015, alguns cadernos, provas e trabalhos de várias disciplinas cursadas durante o ensino técnico agrícola no IFRS-Sertão. Na segunda rodada de entrevistas que realizei com os participantes do estudo, utilizei esse material escolar na tentativa de fazê-los relembrar as aulas, suas vivências escolares etc. Além disso, para essas "novas" entrevistas, usei a seguinte

\footnotetext{
${ }^{4}$ A EAFS foi criada pela Lei no 3.215, de 19 de julho de 1957, com a denominação Escola Agrícola de Passo Fundo, e o Campus Sertão iniciou seu efetivo funcionamento no ano de 1963. Ressalto que a EAFS, por legislações específicas, demarcações territoriais e até mesmo questões políticas, durante esses mais de 50 anos de história, assumiu outras nomenclaturas. Como no trabalho o que interessa é discutir o momento atual, em que é IFRS Campus Sertão, e o período da década de 1980, em que era EAFS, não apresentarei as demais denominações.
} 
estratégia: apresentei a entrevista transcrita ao entrevistado e solicitei que lesse e completasse (ou suprimisse) alguma ideia. A partir disso, novas questões eram feitas por mim.

Vale aqui pontuar o quão importante foi utilizar os textos transcritos e o material escolar para as novas entrevistas. Por meio desses instrumentos, percebo que os novos relatos ficaram mais ricos em detalhes. Importa salientar que, durante a leitura das transcrições das respectivas entrevistas, os entrevistados, a cada linha, procuravam reconhecer-se, dizendo: "mas fui eu mesmo que falei isso?"; "nossa, como falo difícil às vezes!”; "nessa parte, nem eu entendo o que disse, imagina você!”.

Também saliento que percebi, em suas falas, a preocupação em usar corretamente, em cada exemplo citado ou em cada pensamento expresso, os termos técnicos agropecuários ou científicos. Associo isso ao fato de dois deles serem bolsistas de Iniciação Científica desde que começaram a cursar agronomia. Assim, observo que esses participantes expressam os modos como foram subjetivados pelo discurso tecnocientífico. Nesse contexto, busquei fazer de cada entrevista um exercício de escuta sensível. A seguir apresento algumas características do princípio pedagógico do "aprender pela pesquisa".

\section{Tecnociência e seus Entendimentos}

As palavras de Bensaude-Vicent, destacadas a seguir, evidenciam alguns sentidos que estou atribuindo ao conceito de tecnociência no estudo, visto que este conduzirá as discussões que pretendo empreender. Para a autora, “[...] o conceito de tecnociência é bem mais diverso do que uma simples inversão de hierarquia entre ciência e técnica [...]”. Em outras palavras trata-se de "uma mudança de "regime" [...] marcado pela entrada em cena das políticas científicas e das agências de meios que "alimentam" a pesquisa" (BENSAUDE-VINCENT, 2013, p. 21).

Neste artigo, assumo o discurso da tecnociência definida não apenas como integração

entre ciência e tecnologia, conforme é defendido por Bensaude-Vincent (2013) e Castelfranchi (2008) mas como "[...] acontecimento que funciona no interior de uma específica economia de poder e que é caracterizado pela interação e a retroalimentação mútua do capitalismo, da ciência e da tecnologia” (CASTELFRANCHI, 2008, p. 7). A tecnociência contemporânea é lida como um "dispositivo recombinante", o que significa compreendê-la como “[...] o entrelaçamento entre os dispositivos de produção de conhecimento científico, as técnicas e o capitalismo no interior da racionalidade de governo atual" (CASTELFRANCHI, 2008, p. 8-9, grifos do autor). 


\section{Alguns Aspectos sobre o Currículo do Curso}

A modernização ${ }^{5}$ do campo brasileiro consolidou-se, ao longo das últimas cinco décadas, como um processo dinâmico e vinculado aos avanços da tecnociência (BALSAN, 2006). Dito de outra forma, a tecnociência passa a ocupar um lugar de destaque nesse processo, em que os avanços tecnocientíficos são considerados, por autores como Buainain et al. (2014), como a mola propulsora do cenário atual do setor agropecuário brasileiro. Também destaco que esse processo é marcado por muitos conflitos, que vão desde o aumento do desemprego no campo e o êxodo rural até problemas ambientais e as sempre presentes polêmicas sobre o plantio e a comercialização das plantas transgênicas (TOLEDO, 2017).

Ao examinar o Projeto Pedagógico do curso Técnico em Agropecuária do IFRS-Sertão (IFRS-SERTÃO, 2011), constatei que algumas disciplinas da área técnica do curso ali elencadas estão vinculadas à modernização do setor agropecuário brasileiro, ocorrida nas últimas décadas. A atual grade curricular do curso Técnico em Agropecuária estudado na pesquisa contempla disciplinas enfocadas na gestão da propriedade rural. Como relataram uma técnica agrícola que finalizou o curso em 2015 e um técnico agrícola egresso de 2012:

[...] A gente teve também [a disciplina de] Gestão rural I, o professor usava o Excel pra controle dos gastos, [para] fazer a contabilidade da nossa propriedade rural. [...]. O professor na disciplina do outro semestre, Gestão rural II, ele deu essa mesma atividade, só que direcionou todo mundo para a bovinocultura. A gente teve que medir cerca, também teve que usar GPS para delimitar espaço da bovinocultura, até os gastos com medicamento, colocar o nome de todos os medicamentos que tinha, colocar tudo na planilha e apresentar para o professor e tinha que joga na planilha do Excel (Maria - Entrevista realizada em fevereiro de 2016, grifos meus)

Em planejamento e projeto no terceiro ano, também tinha atividades em aula assim, simulávamos à integração da pecuária e lavoura, com várias atividades e colocava despesas e via o que dava mais lucros, isso era saber gerenciar uma propriedade, que em tempos de crise, precisamos largar de algo que não dá lucro e ver o que vai ajudar a recuperar o orçamento da propriedade (Gabriel - $2^{\mathrm{a}}$ Entrevista realizada em novembro de 2015, grifos meus).

A formação do curso Técnico em Agropecuária do IFRS-Sertão, como enfatizo anteriormente, contempla disciplinas vinculadas à área de gestão da propriedade rural,

\footnotetext{
${ }^{5}$ A cada década que passa, novas formas de inserção de tecnologia são feitas no processo de modernização do setor agropecuário brasileiro, e, cada vez mais, eleva-se a produtividade e restringe-se a área de plantio, reduzindo-se o número de produtores que têm conseguido acompanhar este padrão tecnológico. Marginalizada desse processo, encontra-se a agricultura familiar (RUBELO, 2004, p. 12). Os impactos ambientais, econômicos e sociais acarretados pelo progresso tecnológico no campo brasileiro são "[...] decorrentes do uso intensivo dos pacotes tecnológicos, na mecanização do trabalho, na união entre agricultura e indústria, na monocultura, no latifúndio e no consumismo desmedido, principalmente dos países desenvolvidos" (ZAMBERLAM; FRONCHETI, 2001, p. 31).
} 
evidenciando a importância da formação do empresariamento do campo. Isto é, ressalta a importância de as atividades da propriedade rural serem organizadas seguindo a lógica do mercado econômico neoliberal.

A propriedade rural é vista como uma "empresa", precisando ser administrada para que possa ser "competitiva" na atual conjuntura econômica neoliberal em que o campo está. Além disso, o curso também oferece disciplinas como "Propagação de Plantas" e "Cultivo in vitro", cujos objetivos são, respectivamente, "conhecer técnicas de reprodução dos vegetais" (IFRS-SERTÃO, 2011, p. 42) e "proporcionar aos alunos novas técnicas de propagação de plantas realizadas em laboratório (Cultivo in vitro)" (IFRS-SERTÃO, 2011, p. 61). Por exemplo, nas aulas das disciplinas técnicas - Culturas Anuais, Cultivo In Vitro etc. -, eram utilizadas sementes de culturas existentes; a partir de experiências utilizando diferentes profundidades de plantio, espaçamentos entre linhas de semeadura etc., os alunos e professores obtinham novos resultados do manejo e da produção da cultura usada no experimento ou "ensaio".

\section{A Educação Matemática e a Tecnociência na Condução do Currículo do Ensino Agrícola do IFRS-Sertão}

Conforme mostra o trabalho de Valero (2013a), na contemporaneidade, os discursos da educação matemática, por meio da matemática escolar, fabricam um "sujeito racional, objetivo, universal" comprometido em tornar-se um "cidadão cosmopolita moderno" (VALERO, 2013b, p. 9, tradução minha). Assim, os efeitos produzidos pelo discurso da educação matemática na produção das subjetividades dos sujeitos escolares; os modos como esse discurso agiu sobre os estudantes, conduzindo as suas condutas e fazendo-os conduzir a si mesmos (autogovernar-se), ou seja, governando a todos e a cada um, subjetivando os de acordo com a racionalidade de seu tempo a partir de agora será analisado.

Nessa linha de entendimento, uma das verdades postas em movimento na área da educação matemática é a de "que a matemática é poderosa e a educação matemática empodera" (KNIJNIK; VALERO; JØRGENSEN, 2014, p. 2, tradução minha). Na analítica realizada por alguns pesquisadores (VALERO; KNIJNIK, 2015; KNIJNIK; VALERO; JØRGENSEN; 2014), fazer uso do conceito de governamentalidade nas discussões na área da Educação Matemática possibilita expandir o entendimento de como a educação matemática "fabrica a criança desejada nas sociedades contemporâneas" (VALERO; KNIJNIK, 2015, p. 33). 
Em outras palavras, trata-se de considerar "[...] um discurso produzido em diferentes esferas da vida social, por meio de políticas da educação pública, programas escolares, livros didáticos, de pesquisa, a prática de sala de aula, exames e assim por diante" (KNIJNIK; VALERO; JØRGENSEN, 2014, p. 3, tradução minha). Estas áreas não se apresentam isoladas; pelo contrário, interagem umas com as outras na produção de verdades que moldam e compõem o discurso da educação matemática (KNIJNIK; VALERO; JØRGENSEN, 2014). Portanto, fazendo uso da "[...] analítica da governamentalidade, podemos assumir que a Educação Matemática é parte de um dispositivo que conduz não só a conduta dos pesquisadores, mas também de todos os que fazem parte das práticas de Educação. Matemática”, ou seja, professores, alunos, pais etc. (KNIJNIK; VALERO; JØRGENSEN, 2014, p. 3, tradução minha).

Essa afirmação nos remete ao que Foucault (2008a, 2008b) escreve sobre os diferentes significados que podem ser atribuídos ao uso do governo: "o governo como uma relação entre sujeitos e o governo como uma relação consigo mesmo" (CASTRO, 2009, p. 190). Nesse sentido, Foucault nomeou de governamentalidade "o encontro entre as técnicas de dominação exercidas sobre os outros e as técnicas de si mesmo" (AVELINO, 2011, p. 29). O filósofo esclarece que quem é dirigido se deixa dirigir devido a um propósito exterior. Assim, esse deixar-se conduzir diz respeito à relação de si consigo mesmo. Nas palavras do filósofo, "a fórmula da direção no fundo é: 'eu obedeço livremente a isso que tu queres que eu queira, de maneira que eu possa estabelecer uma certa relação de mim comigo mesmo"” (FOUCAULT, 2011, p. 100). É esse complexo movimento de curvar-se, livremente, sobre si mesmo que Foucault nomeou de subjetivação.

$\mathrm{Na}$ análise do material de pesquisa, que a seguir apresento, tomo a governamentalidade no sentido de como o governo, pelas práticas da educação matemática gestada na disciplina de Matemática e da educação matemática presente nas disciplinas técnicas, produz o futuro técnico agrícola do IFRS-Sertão, em conformidade com a ordem do discurso de cada tempo estudado. Levando em conta essa analítica, a questão a ser respondida refere-se a como "[...] a maquinaria escolar está instituindo novos processos de subjetivação e fabricando novos sujeitos" (VEIGA-NETO, 2008, p. 55) em particular com relação à educação matemática presente no espaço e tempo estudado nesta pesquisa.

Trata-se de pesquisar as mudanças que estão acontecendo “[...] nas máquinas, artefatos e dispositivos que, ao mesmo tempo que transformam a si mesmos, transformam (diretamente) os sujeitos que tomam para si e (indiretamente) a sociedade" (VEIGA-NETO, 
2008, p. 55). Veiga-Neto (2008, p. 5) enfatiza que é por meio da Educação que os indivíduos são “[...] introduzidos em um grupo social e moldados pelas formas-de-vida ali partilhadas, de modo a imergir nas condições materiais e nos jogos de linguagem que são singulares e próprios do grupo que os recebe".

Um primeiro resultado produzido pelo exercício analítico que realizei com os documentos - Projeto Pedagógico do Curso (2011) e Plano Pedagógico (BRASIL, 1980) - e, em especial, os documentos relativos à disciplina de Matemática, constatei que tanto no material atual como no que estava em vigor nos anos de 1980, a lista de conteúdos da disciplina matemática coincidia. No documento dos anos de 1980, não se especificam detalhes, como objetivo(s) da disciplina ou referências bibliográficas, ao contrário do documento atual, que apresenta essas especificações. Além disso, estão presentes algumas características que, a partir de agora, apresento.

Os trechos retirados dos cadernos de matemática do segundo ano do curso - do recémformado e do egresso de 1983 - indicam a presença do formalismo nas definições de ciclo trigonométrico e de circunferência e suas medidas, bem como na explicitação do conceito de cilindro. Considerando os dois tempos analisados no trabalho, uma mesma ordenação no processo de ensino se faz presente em cada conteúdo abordado: primeiro, o conceito é enunciado; a seguir, há um ou mais exemplos e, em seguida, listas de exercícios, pautadas por questões, na maioria das vezes, semelhantes ou iguais aos exemplos. Assim como apontado por Giongo (2008), também em minha análise documental percebi o estabelecimento de uma ordem, uma hierarquia e uma sequência para a matemática escolar que regula o modo de pensar dos futuros técnicos agrícolas. Isso me fez pensar que "operações de seleção e hierarquização foram postas em ação" (GIONGO, 2008, p. 141) no curso, em ambos os momentos estudados, as quais acabaram instituindo uma determinada maneira de ministrar os conteúdos da disciplina Matemática.

Nos dois períodos estudados nesta pesquisa, identifiquei uma quantidade significativa de exercícios após cada conteúdo apresentado. Esses exercícios eram semelhantes aos exemplos trabalhados pela professora e, por isso, prezavam por rigor, ordem, abstração e formalismo. Quando me refiro a exercícios semelhantes, digo que eles tinham um enunciado similar, ou o enunciado idêntico ao dos exemplos, somente com alteração dos valores numéricos. As operações matemáticas expressas no material escolar analisado foram efetuadas com o auxílio de "algoritmos escritos, que se sustentam por uma racionalidade específica, que exige o cumprimento de regras" (WANDERER; KNIJNIK, 2008, p. 561). 
Essa procura incessante pela ordem e por um saber rigoroso, preciso, exato e absoluto fez com que a matemática, desde o século XIX, fosse vista como "um instrumento essencial e poderoso no mundo moderno", o que a tornou um meio de validação em todas as áreas do conhecimento (D’AMBROSIO, 2011, p. 75). A repetição exigida pelas listas de exercícios da matemática conduz ao domínio dessa gramática: o uso, ainda que, em certo sentido, livre, "é regido por regras que distinguem o uso correto do incorreto das palavras" (CONDÉ, 2004, p. $89)$.

Desse modo, "é o conjunto dessas regras, que possuem um aspecto dinâmico e estão em contínuo fluxo, que compõem a Gramática” (CONDÉ, 2004, p. 89). Em concordância com essas ideias, Knijnik et al. (2012) discutem a supremacia da cultura escrita sobre a oral na gramática da disciplina Matemática e consideram que essa escrita, regida pelo formalismo e abstração das sentenças matemáticas e dos algoritmos, hegemonicamente se faz presente na matemática escolar. A matemática escolar "toma emprestada" (KNIJNIK, 2006b, p. 3), da matemática acadêmica, "sua linguagem formal e abstrata" (KNIJNIK, 2006b, p. 3).

Já a oralidade distancia-se dessa matemática acadêmica e da matemática escolar por ser uma racionalidade que opera mediante outras regras e estratégias. Pelo exposto, destaco que pensar e compreender o discurso matemático "[...] como protótipo do nascimento e do devir de todas as outras ciências" é correr "[...] o risco de homogeneizar todas as formas singulares de historicidade, reconduzir à instância de um único corte todos os limiares diferentes que uma prática discursiva pode transpor [...]". A matemática foi “[...] seguramente modelo para a maioria dos discursos científicos em seu esforço de alcançar o rigor formal e a demonstratividade; mas, para o historiador que interroga o devir efetivo das ciências ela é um mau exemplo [...]" (FOUCAULT, 2013, p. 228).

A seguir, apresento um conjunto de excertos que me possibilitaram perceber como se dá o processo de aprender e ensinar na disciplina de Matemática. Esse material também permite identificar as enunciações recorrentes que circulavam no discurso da educação matemática da disciplina de Matemática que indicam os jogos de linguagem ${ }^{6}$ praticados ali.

\footnotetext{
6 Para Wittgenstein, a concepção de linguagem está associada ao uso feito da palavra ou expressão em determinado contexto, isto é, em uma específica forma de vida (CONDÉ, 1998). A significação de uma palavra emerge do uso que dela fazemos nas variadas situações. Portanto, não existe uma única linguagem, mas "simplesmente linguagens", isto é, "uma variedade imensa de usos, uma pluralidade de funções ou papéis que poderíamos compreender como jogos de linguagem" (CONDÉ, 1998, p. 86, grifos do autor). "Se a mesma expressão linguística for usada de outra forma ou em outro contexto, sua significação poderá ser outra, isto é, poderá ter uma significação totalmente diversa da anterior, dependendo do uso no novo contexto" (CONDÉ, 1998, p. 89). A esse respeito, Wittgenstein salienta que se pode "para uma grande classe de casos de utilização
} 
Escolhi esses excertos porque neles está expressa, de modo recorrente, a ausência de recursos tecnológicos nas aulas da disciplina de Matemática. Nesse sentido, enfatiza o egresso, "nunca fomos fazer nada de diferente, como ir ao laboratório de informática que tinha novo, com computadores novos".

Com relação à disciplina de Matemática praticada no curso atualmente, fica evidenciada a existência de "bastante exercício". Maria pontua que as listas de exercícios eram "pra gente fazer como tema de casa" e, "na próxima aula, a gente corrigir junto" com a professora. Com relação ao número significativo de "exercícios", a recém-formada considera que "ajudava muito, mas muito mesmo, a gente a aprender". Desse modo, por meio da lista de exercícios como tarefa de casa, "o professor conseguia meio que analisar como que estava o andamento, como que estava o nível da turma". O quadro era o recurso usado com frequência nas aulas de matemática. O livro didático é enfatizado pelos recémformados como ferramenta utilizada pelos professores em suas aulas de matemática.

Outra questão pertinente, que emergiu do material de pesquisa analisado, diz respeito aos jogos de linguagem que circulavam na disciplina de Matemática. Com relação a isso, apresento algumas enunciações extraídas do material de pesquisa: "decorava as fórmulas"; "se [...] não for fazendo passo por passo, se perde viu, se perde mesmo, tem que fazer passo por passo"; "mas, mesmo assim, tinha que decorar as fórmulas"; "tem que ler o problema e prestar atenção, entender o que pede no problema, pra ver qual usar [fórmula]". Como explicita o egresso, os estudantes deveriam resolver tanto as questões das listas de exercícios, quanto as questões presentes nas provas e trabalhos, "colocando a fórmula primeiro" e, "no lugar do seno, quanto ele vale", de acordo com o "que a professora deu aqui no começo", no enunciado da questão; por fim, "vai fazendo, fazendo a conta, e coloca aqui e passa pra cá [detalhes da resolução que ele estava olhando no caderno] e até chegar à resposta".

Em suma, "tem que fazer passo por passo" e "tem que seguir certinho em cada linha, fazer uma coisa [refere-se a uma parte do cálculo]”. Também é possível verificar que, nas avaliações de matemática, "a professora cobrava tudo [...], fórmulas de seno, cosseno”; a exigência era "a questão toda, toda ela feita, todos os passos". Caso o aluno não seguisse o modelo de resolução visto nas aulas, isto é, as orientações da professora para resolver um cálculo, "ela [professora] dava meia questão".

da palavra 'significação' - se não para todos os casos de sua utilização - explicá-la assim: a significação de uma palavra é seu uso na linguagem” (WITTGENSTEIN, 1999, § 43, p. 43, grifos do autor). 
Volta-se agora a atenção às disciplinas que compõem o currículo da formação técnica do curso analisado no estudo, em especial, sobre a educação matemática presente nas disciplinas técnicas. A partir do exame das entrevistas conclui que, enquanto a educação matemática da disciplina de Matemática manteve a sua abordagem abstrata e formal tradicional, a educação matemática associada às tarefas agrícolas, praticada nas disciplinas técnicas, passou a incluir novos recursos tecnológicos. Os excertos abaixo apontam para essa conclusão:

O professor de mecanização agrícola trabalhava bastante com GPS até, como na matéria dele nós tínhamos que usa muito GPS, ele incentivava muito e ensinava usar os aplicativos de celular pra usar no trabalho. [...] também em Gestão rural, o professor usava o Excell pra controle dos gastos e tudo tipo fazer a contabilidade da nossa propriedade rural. [...] Ah! A disciplina de topografia, assim, a gente tirava os pontos pelo teodolito moderno, o professor disse que eram os mais modernos e tinham comprado novinhos a pouco tempo, [...] mas esses aparelhos também dão os cálculos mais exatos (Maria - Entrevista realizada em fevereiro de 2016, grifos meus).

Eu tive que fazer um dimensionamento de sistema de irrigação na aula de irrigação, por exemplo, eu dizia pra o professor é muito mais fácil fazer uma planilha no Excell, tu digita a fórmula e os dados e ele dá pronto. [...] Por exemplo em irrigação tem muito cálculo pra fazer, tem muita fórmula, você precisa dimensionar reservatório, precisa dimensionar bomba, [...] teve algumas aulas que nós fazíamos os cálculos no Excell, o professor levava nós no laboratório de informática e ensinava nós fazer no Excell (Gabriel - $2^{\mathrm{a}}$ Entrevista realizada em novembro de 2015, grifos meus).

O fato de a educação matemática das disciplinas técnicas ter incluído novas tecnologias em suas práticas pedagógicas me fez questionar o indagado por Veiga-Neto (1999, p. 5): nos tempos e espaços estudados nesta pesquisa, é possível dizer que o currículo das disciplinas técnicas é um "artefato que em termos gerais, quais (seriam) os objetivos da escolarização na e para a lógica neoliberal?”. Acompanhando o autor, considero que a escola, inserida nas tramas do neoliberalismo, tem como uma das suas funções "criar/moldar o sujeito-cliente" (VEIGA-NETO, 1999, p. 15).

Isso não implica, necessariamente, a demissão daquele propósito que conduziu a escolarização na “[...] Modernidade: uma escola pensada - e ainda vem funcionando - como uma imensa maquinaria de confinamento disciplinar, a maior encarregada pela ampla normalização das sociedades modernas" (VEIGA-NETO, 1999, p. 15). Em ambos os casos, a escola deve desempenhar papéis fundamentais, de modo que prepare sujeitos que sejam capazes de "[...] compreender e manejar — ou, pelo menos, sobreviver em... — cenários 
fantasmagóricos e de constante tensão entre o individual e o cooperativo, entre o local e o global" (VEIGA-NETO, 1999, p. 18).

Nessa linha de entendimento, Knijnik (2015, p. 12) afirma que a "lógica neoliberal que conforma o mundo globalizado de hoje opera em cada um de nós". Assim, cada uma de nós está diretamente envolvido na condução da conduta das "[...] novas gerações e na condução de nossas próprias condutas em uma determinada direção, a saber, na constituição de indivíduos que aprendam, por exemplo, a ser flexíveis, competitivos, empreendedores de si mesmos..." (KNIJNIK, 2015, p. 12).

A seguir, apresento alguns fragmentos extraídos das entrevistas realizadas com os egressos da década de 1980, a fim de mostrar aspectos dos modos como a educação matemática operava nas disciplinas técnicas nos anos de 1980.

Pesquisadora: Estou olhando aqui, o caderno de topografia de um aluno que estudou na mesma época que o senhor. Deixa lhe mostrar [mostrei]. Será que o profissional, o técnico agrícola, faz todos esses cálculos como está aqui [mostrei] no caderno?

Luis: Hum! Mas hoje o profissional não faz mais à mão, tudo é informatizado, tem programa de computador pra fazer tudo, tem GPS, aparelhos modernos. Lá em 1988 e 89, quando eu comecei como técnico na cooperativa, nessa época, a topografia era assim óh! Eu caminhava 7 dias pra fazer demarcação dos limites das propriedades, fazendo terraço. E[pensativo] na aula dessa matéria tinha umas quantas fórmulas e eu resolvia a mão esses cálculos e eu sabia resolver tudo [mostrou no caderno de topografia], com tudo isso de cálculo como aparece aqui [mostrou no caderno].

Pesquisadora: Era usado algum instrumento nas aulas práticas de topografia?

Luis: Hum! Às vezes, tinha um ou outro teodolito simples [...]. Olha aí o caderno [mostrou o caderno], tinham muitas fórmulas pra resolver à mão e na aula prática nós usávamos um teodolito simples e básico! Mas nem sempre nós usávamos o teodolito, porque [pensativo] tinham poucos, poucos mesmo [teodolitos] e, a turma era grande. Acho que por isso o professor quase nem levava o teodolito pra aula no campo [aula prática]. Eu sei que tinha fórmulas pra calcular. Daí como nós fazíamos? O professor levava nós pra o campo [refere-se as aulas práticas] e nós fazíamos tudo a mão, com trena grande, contando os passos, marcando os pontos com umas estacas e tal. Hoje em dia, você digita os pontos no GPS e pronto! Na época que eu estudava [na EAFS] e me formei, e logo que comecei a trabalha a gente calculava a mão. Tinha que entrar no mato, atravessar rio e marcar os pontos, levava dias pra fazer o que hoje se faz numa tarde. [...]. Era muito precário os instrumentos na minha época de escola [EAFS]. Luis - 2a Entrevista realizada em outubro de 2015, grifos meus).

No passado, com relação à disciplina de Topografia, que compõe o currículo da formação técnica, o técnico agrícola, que se graduou na instituição lócus do estudo, destaca que "tinha muitas fórmulas pra resolver a mão, e, na aula prática, nós usávamos um teodolito simples e básico”. Conforme explicita, o uso de instrumentos, como teodolito, nas aulas práticas era raro: "às vezes, tinha um ou outro teodolito simples”. Ele argumenta que 
havia poucos aparelhos - teodolitos -, considerando que a turma era numerosa, por isso, " $o$ professor quase nem levava o teodolito pra aula no campo [aula prática]”.

Além disso, o participante do estudo, considerando os anos de 1988 e 1989, quando iniciou seu trabalho como técnico agrícola em uma das cooperativas da região norte do nosso estado, afirma o seguinte: "nessa época, a topografia era assim, oh! Eu caminhava sete dias pra fazer demarcação dos limites das propriedades, fazendo terraço. Tinha teodolito pra fazer, mas era muito simples, era tudo no braço mesmo [refere-se a ser uma tarefa manual]”. Em muitas situações, "fica mais no olho [...] quero dizer, que não era preciso [refere-se à exatidão das medidas]. Nós fazíamos a mão, e dava um valor, e com o teodolito a gente marcava, sem muita precisão, dava muito diferente”. Esse aspecto vai de encontro ao cenário dos dias atuais, em que o técnico agrícola "não faz mais a mão, tudo é informatizado, tem programa de computador pra fazer tudo, tem GPS, aparelhos modernos".

Esses excertos estão em conformidade com o que foi brevemente mostrado no que se refere ao processo de modernização do campo, iniciado na década de 1960 e intensificado nos anos 1980. Segundo autores como Pizzolatti (2004) e Buainain et al. (2014), a tecnologia no setor agropecuário brasileiro e mundial continua avançando significativamente nas últimas três décadas e, com isso, modifica os processos de produzir no campo. Isso faz com que o produtor rural e os profissionais envolvidos com o setor busquem aperfeiçoamento constante, para que aprendam por toda a vida.

Nesse cenário, as "práticas de gestão" da propriedade rural são fundamentais para que o agricultor possa competir e manter-se competitivo no mercado agrícola vigente (PIZZOLATTI, 2004, p. 10), ou seja, os “empreendimentos rurais precisam ter características empresariais" para se manterem "viáveis técnica e economicamente" (PIZZOLATTI, 2004, p. 10). Tais considerações levam-me a afirmar que, no passado, as práticas pedagógicas na educação matemática gestada nas disciplinas técnicas acompanharam o processo inicial de modernização do campo, uma vez que elas estavam em sintonia com a racionalidade daquela época, na qual os recursos tecnológicos eram ainda incipientes.

$\mathrm{Na}$ atualidade, a educação matemática presente na formação técnica está em concordância com o discurso da tecnociência, na contemporaneidade. Isso não é surpreendente, tendo em vista o cenário atual de modernização e os efeitos produzidos pelo discurso da tecnociência. As práticas pedagógicas governam os sujeitos escolares na tentativa de produzir um futuro técnico agrícola com condições de atuar no cenário atual do campo brasileiro. Trata-se de um contexto inserido nas tramas da racionalidade neoliberal, que 
indicam ao profissional do setor agropecuário que, para jogar o jogo neoliberal, é necessário ser um sujeito que "aprenda para toda a vida".

Ao comparar a educação matemática praticada na disciplina de Matemática com aquela praticada nas disciplinas técnicas, o Sr. Pedro, que se formou em 1986, salienta que, "nas disciplinas técnicas, os cálculos eram muito mais simples”. Conforme ressalta, "o que a gente via na matemática, a gente acabava não ocupando na parte técnica”, em que "o que sempre ocupava era regra simples de três, a gente acabava resolvendo as coisas assim, com regra de três". Complementa essa ideia exemplificando que, "numa regulagem de uma semeadora, tem as fórmulas específicas, mas dá para, por exemplo, fazer por regra de três. Tu acabas resolvendo, acabas conseguindo fazer o cálculo com regra de três". Ele destaca, quanto às disciplinas técnicas, que "na sala a gente fazia o cálculo com regra de três, assim, no caderno"; quando eles aplicavam esse cálculo nas aulas práticas, por exemplo, na "regulagem da semeadeira, dai a gente ia ajustando os valores que encontramos pela regra”. Segundo o egresso, "na prática, se deu um [...] número quebrado, tinha que colocar ou pra cima ou pra baixo, conforme o que a gente tinha. Às vezes, pela semente que tem, o professor dizia 'vamos colocar pra cima', mas às vezes era pra baixo [refere-se ao arredondamento numérico]".

O técnico agrícola Pedro relatou outro exemplo: "para calcular uma densidade de plantio de uma variedade de soja, nós calculávamos na sala e depois [pensativo] levávamos o resultado pronto para o campo. Chegando lá, o que acontecia? Dependendo do valor que dava no caderno, nós tirávamos o quebrado, tirava o número quebrado [refere-se ao arredondamento], fazíamos [pensativo] ajustes”. Assim, conclui: “às vezes, tu saías com um valor exato ou não, mas não fechava na prática, pelo que o professor falava que tinha que ser, pelo que é recomendado. Tem muita coisa que tem que prestar atenção na prática, sabe? Dai tem que aproximar, e te digo [que] é assim até hoje [refere-se ao exercício da profissão de técnico agrícola]. Na prática, tem isso, tem que arrumar os números [refere-se às aproximações, aos arredondamentos]".

Em consonância com as ideias acima expostas, afirmo que, na educação matemática gestada nas disciplinas técnicas em sala de aula, era priorizado o uso da escrita e o formalismo, presentes também na disciplina de Matemática. Mas não só isso. Também ali estavam presentes jogos de linguagem que, por exemplo, realizavam um "ajuste" dos valores numéricos encontrados. Acompanhando Knijnik e Giongo (2009), afirmo que, nas disciplinas técnicas, eram postos em prática jogos de linguagem associados a duas diferentes lógicas: 
aqueles praticados nas aulas teóricas, que possuíam semelhanças de família com os da matemática escolar. Por sua vez, os jogos de linguagem matemáticos presentes nas atividades agropecuárias, ou seja, nas aulas práticas, apresentavam semelhanças de família com aquelas gestadas na forma de vida camponesa (KNIJNIK, 2006a, 2006b).

A esse respeito, a chamada "matemática das disciplinas técnicas" punha em uso a aproximação - o "olhômetro" para referir-se às estimativas - e a oralidade. Essa expressão foi referenciada por alunos e professores entrevistados no estudo realizado por Knijnik e Giongo (2009). Diferentemente da assepsia, do formalismo e da abstração presentes na educação matemática da disciplina Matemática, os alunos " [...] valiam-se de regras diferentes daquelas conformadas nessa disciplina, quando thes era solicitado que resolvessem, nas disciplinas técnicas, problemas ligados à lida do campo" (KNIJNIK; GIONGO, 2009, p. 71). Assim, mais do que obedecer às regras ditadas pela matemática da disciplina Matemática, "[...] a matemática das disciplinas técnicas estava amalgamada às práticas cotidianas produtivas e sustentada por uma gramática cujas regras incluíam arredondamentos e estimativas" (KNIJNIK; GIONGO, 2009, p. 72).

\section{Palavras Finais}

Nesta seção, que encerra o artigo, destaco mais uma vez que o propósito deste estudo foi examinar os efeitos do discurso da tecnociência presentes na educação matemática praticada na disciplina de matemática e nas disciplinas técnicas do Curso Técnico em Agropecuária do IFRS-Sertão. Conforme ressaltei, a escrita deste texto foi conduzida pelas questões: como a formação do técnico agrícola do IFRS-Sertão é atingida por essas configurações? Em particular, na área da educação matemática, como isso se realiza?

A análise do material de pesquisa - entrevistas com egressos do curso, documentos institucionais e materiais escolares - que teve principalmente, como balizas teóricas as noções advindas de Michel Foucault e seus comentadores, mostrou que nas últimas três décadas, a listagem de conteúdos da disciplina de Matemática não se alterou. A educação matemática da disciplina Matemática manteve sua abordagem abstrata e formal, e a educação matemática presente nas disciplinas técnicas alinhou-se com o discurso da tecnociência, incluindo recursos tecnológicos.

Resumidamente, no mundo globalizado em que vivemos, a tecnociência vinculada à racionalidade neoliberal é sustentada por determinadas verdades que atuam sobre os sujeitos, conduzindo-os e fazendo-os conduzir a si mesmos. Nesse contexto, a tecnociência assume 
uma posição de destaque na produção do conhecimento científico e é concebida como fundamental para que indivíduos e a nação tenham um futuro próspero. Assim, como apresentei ao longo do texto, esse cenário reverbera no currículo escolar de curso Técnico Agrícola do IFRS-Sertão, de modo que

[...] a tecnociência é inevitável. Ela é uma máquina, uma locomotiva em marcha, e sua marcha e neutral e imanente: não pode e não deve ser interrompida. Não pode e não deve ser obstaculizada, dirigida, politizada. Mas esta inexorabilidade não e apenas efeito de um aparato ideológico: e parte do funcionamento de um dispositivo que contribui, ao mesmo tempo, para modular a construção dos saberes, a constituição dos sujeitos, o funcionamento do governo de si e dos outros (CASTELFRANCHI, 2008, p. 10 , grifos do autor).

Para finalizar, a ciência e a tecnologia - a tecnociência - adentram no contexto da Educação Profissional Técnica Agrícola de nível médio e, aos poucos, de forma estratégica, desmistificam a ideia de algo inacessível a todos; ou seja, o saber científico e tecnológico passa a ser visto como um investimento por parte do aluno e do Estado.

\section{Referências}

AVELINO, Nildo. Foucault e a anarqueologia dos saberes. In: FOUCAULT, Michel. Do governo dos vivos: curso no Collège de France, 1979-1980 (excertos). Tradução, transcrição e notas de Nildo Avelino. São Paulo: Centro de Cultura Social; Rio de Janeiro: Achiamé, 2011. p. 17-37.

BALSAN, Rosane. Impactos decorrentes da modernização da agricultura brasileira. Campo Território: Revista de Geografia Agrária, Uberlândia, v. 1, n. 2, p. 123-151, ago. 2006.

BENSAUDE-VICENT, Bernadette. As vertigens da tecnociência: moldar o mundo átomo por átomo. São Paulo: Ideias \& Letras, 2013.

BOCASANTA, Daiane Martins; KNIJNIK, Gelsa. Dispositivo da tecnocientificidade e iniciação científica na educação básica. Currículo sem Fronteiras, Porto Alegre, v. 16, n. 1, p. 139-158, jan./abr. 2016.

BRASIL. Ministério da Educação e Cultura. Secretaria de Ensino de $1^{\circ}$ e $2^{\circ}$ graus, Coordenação Nacional de Ensino Agropecuário. Plano Pedagógico. Brasília: MEC/SEPS/COAGRI, 1980.

BUAINAIN, Antônio Márcio et al. O mundo rural no Brasil do século 21: a formação de um novo padrão agrário e agrícola. Brasília: Embrapa, 2014. 
CASTELFRANCHI, Juri. As serpentes e o bastão: tecnociência, neoliberalismo e inexorabilidade. 2008. Tese (Doutorado em Filosofia) - Programa de Pós-Graduação em Filosofia, Instituto de Filosofia e Ciências Humanas, Universidade Estadual de Campinas, Campinas, SP, 2008.

CASTRO, Edgar. Vocabulário de Foucault: um percurso pelos temas, conceitos e autores. Belo Horizonte: Autêntica, 2009.

CONDÉ, Mauro Lúcio Leitão. Wittgenstein: linguagem e mundo. São Paulo: Annablume, 1998.

CONDÉ, Mauro Lúcio Leitão. As teias da razão: Wittgenstein e a crise da racionalidade moderna. Belo Horizonte: Argvmentvm, 2004.

D’AMBROSIO, Ubiratan. Etnomatemática - elo entre as tradições e a modernidade. 4. ed. Belo Horizonte: Autêntica, 2011.

FILHO, Jose Eustáquio Ribeiro Vieira. Transformação histórica e padrões tecnológicos da agricultura brasileira. In: BUAINAIN, Antônio Márcio et al. O mundo rural no Brasil do século 21: a formação de um novo padrão agrário e agrícola. Brasília: Embrapa, 2014. p. 395422.

FISCHER, Rosa Maria Bueno. Trabalhar com Foucault: arqueologia de uma paixão. Belo Horizonte: Autêntica, 2012.

FOUCAULT, Michel. Segurança, território, população: curso dado no Collège de France. São Paulo: Martins Fontes, 2008a.

FOUCAULT, Michel. Nascimento da Biopolítica. São Paulo: Martins Fontes, 2008b.

FOUCAULT, Michel. Do governo dos vivos: curso no Collège de France, 1979-1980: excertos. Tradução, transcrição e notas de Nildo Avelino. 2. ed. Rio de Janeiro: Achiamé, 2011.

FOUCAULT, Michel. Arqueologia do saber. 8. ed. Rio de Janeiro: Forense Universitária, 2013.

GIONGO, Ieda Maria. Disciplinamento e resistência dos corpos e dos saberes: um estudo sobre a educação matemática da Escola Estadual Técnica Agrícola Guaporé. 2008. Tese (Doutorado em Educação) - Programa de Pós-Graduação em Educação, Universidade do Vale do Rio dos Sinos - UNISINOS, São Leopoldo, 2008.

INSTITUTO FEDERAL DE EDUCAÇÃO, CIÊNCIA E TECNOLOGIA DO RIO GRANDE DO SUL (IFRS-SERTÃO). Projeto Pedagógico do Curso Técnico em Agropecuária Integrado ao Ensino Médio (PPC). Sertão, 2011. Documento interno do IFRS-Sertão. 
JØRGENSEN, Kenneth Mølbjerg; STRAND, Anete M. Camille. Material Storytelling Learning as Intra-Active Becoming. In: JØRGENSEN, Kenneth Mølbjerg; LARGARCHAMARTINEZ, Carlos. Critical Narrative Inquiry - Storytelling, Sustainability and Power.New York:Nova Publishers 2014. p.53-72.

KNIJNIK, Gelsa. Educação Matemática, culturas e conhecimento na luta pela terra. Santa Cruz do Sul: EDUNISC, 2006a.

KNIJNIK, Gelsa. Educação matemática e diferença cultural: o desafio de "virar ao avesso" saberes matemáticos e pedagógicos. In: Encontro Nacional de Didática e Prática de Ensino ENDIPE. Anais do Encontro Nacional de Didática e Prática de Ensino. Recife: Bagaço, 2006b. p. 1-8.

KNIJNIK, Gelsa. Fazer perguntas... ter a cabeça cheia de pontos de interrogação: uma discussão sobre etnomatemática e modelagem matemática escolar. Unión, San Cristobal de La Laguna, v. 44, p. 1023, 2015.

KNIJNIK, Gelsa; GIONGO, Ieda Maria. Educação matemática e currículo escolar: um estudo das matemáticas da escola estadual técnica agrícola Guaporé. Zetetiké, Campinas, v. 17, n. 32, jul./dez. 2009.

KNIJNIK, Gelsa et al. Etnomatemática em movimento. Belo Horizonte: Autêntica, 2012.

KNIJNIK, Gelsa; VALERO, Paola; JØRGENSEN, Kenneth Mølbjerg. El discurso de la educación matemática en la perspectiva de la gubernamentalidad. II Seminario Internacional pensar de outro modo: Resonancias de Foucault en la educación. 2014. p. 1-10.

LATOUR, Bruno. Ciência em ação: como seguir cientistas e engenheiros sociedade afora. São Paulo: Ed. Unesp, 2011.

PIZZOLATTI, Ives José. Visão e Conceito de Agribusiness. 2004. Disponível em: http://bis.sebrae.com.br/bis/conteudoPublicacao.zhtml?id=298. Acesso em: 8 mar. 2016.

RUBELO, João Geraldo Nunes. O processo de modernização da agricultura brasileira pluriatividade da agricultura familiar. Economia e Pesquisa, Araçatuba, v. 6, n. 6, p. 1 08122, mar. 2004.

SILVA, Roberto Rafael Dias da. A constituição da docência no Ensino Médio no Brasil contemporâneo: uma analítica de governo. 2011. Tese (Doutorado em Educação) - Programa de Pós Graduação em Educação, Universidade do Vale do Rio dos Sinos - UNISINOS, São Leopoldo, 2011.

SILVEIRA, José Maria da. Agricultura brasileira: o papel da inovação tecnológica. In: BUAINAIN, Antônio Márcio et al. O mundo rural no Brasil do século 21: a formação de um novo padrão agrário e agrícola. Brasília: Embrapa, 2014. p. 373-394. 
SOUZA, Deise Maria Xavier de Barros. Narrativas de uma professora de matemática: uma construção de significados sobre avaliação. 2015. Dissertação (Mestrado em Educação Matemática) - Programa de Pós-Graduação em Educação Matemática, Universidade Federal de Mato Grosso do Sul - UFMS, Mato Grosso do Sul, 2015.

TOLEDO, Neila de Toledo e. Educação matemática e formação do técnico agrícola: entre o "aprender pela pesquisa" e o "aprender a fazer fazendo". 2017. Tese (Doutorado em Educação) - Programa de Pós-Graduação em Educação, Universidade do Vale do Rio dos Sinos - UNISINOS, São Leopoldo, 2017.

VALERO, Paola. Investigación em educación matemática, currículo escolar y constitución de la subjetividade. Anais VII CIBEM, Montevideo, Uruguai, 16 a 20 de setembro, 2013a.

VALERO, Paola. Mathematics for all and the promise of a bright future. Papers for the CERME 8 Conference, Turkey, 2013b, p. 1-10. Disponível em:

$<$ http://vbn.aau.dk/files/76731132/WG10_Valero.pdf>. Acesso em: 28 out. 2016.

VALERO, Paola; KNIJNIK, Gelsa. Governing the modern, neoliberal child through ict reseach in mathematics education. For the Learning of Mathematics, v. 35, n. 2, p. 33-38, Jul. 2015.

VEIGA-NETO, Alfredo. Educação e governamentalidade neoliberal: novos dispositivos, novas subjetividades. Colóquio Foucault, realizado na Universidade do Estado do Rio de Janeiro (UERJ), novembro, 1999. Disponível em:

http://www.lite.fe.unicamp.br/cursos/nt/ta5.13.htm. Acesso em: 20 jun. 2016.

VEIGA-NETO, Alfredo. Crise da Modernidade e inovações curriculares: da disciplina para o controle. In: PERES, Eliane et al. (Orgs.). Trajetórias e processos de ensinar e aprender: sujeitos, currículos e culturas. Porto Alegre: EDIPUCRS, 2008. p. 35-58.

VEIGA-NETO, Alfredo. Estudos biopolíticos e educação na América Latina: avaliação e perspectivas. In: IV Colóquio Latinoamericano de Biopolítica - CLAB, II colóquio Internacional de Biopolítica y Educación - CIBE. Bogotá, 2013. Disponível em: $<$ http://www.michelfoucault.com.br/files/IV\%20CLAB\%20-

\%20II\%20CIBE\%20\%20Encerr.\%20Texto\%20Final\%20para\%20LER\%20-\%206set13.pdf>. Acesso em: 12 jan. 2015.

WANDERER, Fernanda; KNIJNIK, Gelsa. Discursos produzidos por colonos do sul do país sobre a matemática e a escola de seu tempo. Revista Brasileira de Educação, Rio de Janeiro, v. 13, n. 39, set./dez. 2008.

WITTGENSTEIN, Ludwig. Investigações filosóficas. São Paulo: Nova Cultural, 1999.

ZAMBERLAN, Jurandir; FRONCHETI, Alceu. Preservação do pequeno agricultor e o meio ambiente. Petrópolis, RJ: Vozes, 2001. 